\title{
Modeling Cryptosporidium and Giardia in Ground and Surface Water Sources in Rural India: Associations with Latrines, Livestock, Damaged Wells, and Rainfall Patterns
}

\author{
Miles E. Daniels, ${ }^{\dagger}$ Woutrina A. Smith, ${ }^{\dagger}$ Wolf-Peter Schmidt, ${ }^{\ddagger}$ Thomas Clasen, ${ }^{\ddagger}$, \\ and Marion W. Jenkins ${ }^{*},+, \|$
}

\begin{abstract}
${ }^{\dagger}$ Department of Veterinary Medicine and Epidemiology, School of Veterinary Medicine, University of California, Davis, One Shields Avenue, Davis, California 95616, United States

${ }^{\ddagger}$ Faculty of Infectious and Tropical Diseases, London School of Hygiene and Tropical Medicine, Keppel St, London WC1E 7HT, U.K.

${ }^{\S}$ Rollins School of Public Health, Emory University, Atlanta, Georgia 30322, United States

"Department of Civil and Environmental Engineering, University of California, Davis, One Shield Avenue, Davis, California 95616, United States
\end{abstract}

Supporting Information

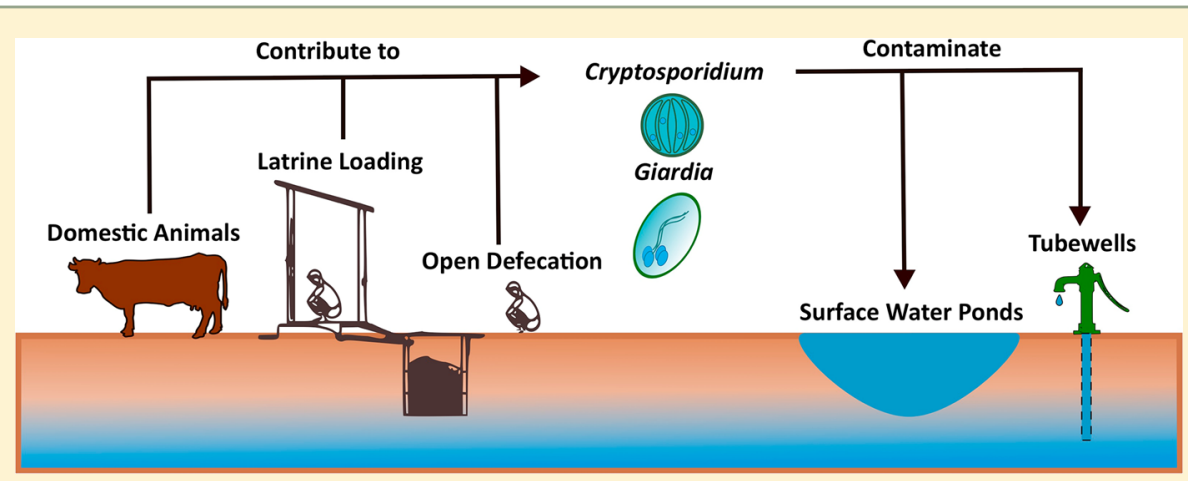

ABSTRACT: Surface and groundwater contamination with fecal pathogens is a public health concern especially in low-income settings where these sources are used untreated. We modeled observed Cryptosporidium and Giardia contamination in community ponds $(n=94 ; 79 \%$ contaminated), deep tubewells (DTWs) $(n=107 ; 17 \%)$, and shallow tubewells (STWs) ( $n=$ 96; 19\%) during the 2012 and 2013 monsoon seasons (June-August) in 60 villages in Puri District, India to understand sources and processes of contamination. Detection of Cryptosporidium and/or Giardia in a tubewell was positively associated with damage to the well pad for DTWs, the amount of human loading into pour-flush latrine pits nearby ( $\leq 15 \mathrm{~m})$ for STWs, and the village literacy rate (for Giardia in STWs). Pond concentration levels were positively associated with the number of people practicing open defecation within $50 \mathrm{~m}$ and the sheep population for Cryptosporidium, and with the village illiteracy rate for Giardia. Recent rainfall increased the risk of Cryptosporidium in STWs (an extreme event) and ponds (any), while increasing seasonal rainfall decreased the risk of Giardia in STWs and ponds. Full latrine coverage in this setting is expected to marginally reduce pond Cryptosporidium contamination (16\%) while increasing local groundwater protozoal contamination (87-306\%), with the largest increases predicted for Cryptosporidium in STWs.

\section{INTRODUCTION}

In much of rural India, local surface water is used for personal and domestic hygiene and local groundwater is used for drinking and cooking, with over half of rural households getting their drinking water from tubewells. ${ }^{1}$ When contaminated with fecal pathogens, these water sources can be a transmission route for diarrheal disease. Among fecal pathogens, the protozoa Cryptosporidium and Giardia are responsible for the majority of detected waterborne disease outbreaks worldwide, ${ }^{2}$ and Cryptosporidium has been identified as a leading cause of moderate-to-severe diarrhea in Indian children $<2$ years old. ${ }^{3}$
To reduce diarrhea and other disease burdens, the Government of India has made significant investments to improve rural sanitation through widespread promotion and construction of household pour-flush latrines. ${ }^{4}$ Under India's Total Sanitation Campaign (2000-2012), an estimated 95 million rural household latrines were installed with government support;

Received: November 25, 2015

Revised: April 12, 2016

Accepted: June 16, 2016

Published: June 16, 2016 
millions more are planned under its Total Sanitation for All Campaign (2012-2022). ${ }^{4}$ Leachate from pour-flush latrines and other on-site sanitation, however, can contaminate local groundwater. Evidence exists for bacterial and viral transport laterally up to 25 and $50 \mathrm{~m}$, respectively, from latrines. ${ }^{5}$ Public health guidelines for the distance between latrines and water points vary by country, with India recommending 3-10 $\mathrm{m}$ and others a distance equal to 25 days travel time for leachate, but these guidelines can be difficult to enforce in rural areas. ${ }^{6-8}$

To our knowledge, no published studies have examined the impact of pit latrines on groundwater contamination for Cryptosporidium and Giardia as indicated by a recent systematic review. ${ }^{5}$ One explanation for the gap is an assumption that their larger size $(4-18 \mu \mathrm{m})$, compared to bacteria (typically $<5 \mu \mathrm{m}$ ) and viruses (typically $<1 \mu \mathrm{m}$ ), precludes Cryptosporidium and Giardia from being transported in groundwater over distances required to reach wells. ${ }^{8}$ Although experimental column studies of groundwater transport indicate a high rate of short-term removal of Cryptosporidium in the first few meters of saturated sandy soils, ${ }^{9,10}$ they also show long-term, low-level transport of Cryptosporidium at longer distances, attributed to remobilization mechanisms that reverse initial filtration/straining. ${ }^{10}$ Because both Cryptosporidium and Giardia can persist for extended periods of time in soil and water ( $>3$ months $)^{11}$ and both pathogens can cause infection at very low dose, ${ }^{12}$ the public health threat from long-term, low-level subsurface transport of Cryptosporidium and Giardia from latrines to wells requires further examination in general, and particularly in the rural Indian context of rapid latrine expansion.

Identifying the causes and implications of environmental contamination for Cryptosporidium and Giardia requires consideration of additional contamination sources and processes beyond groundwater contamination from latrines. Cryptosporidium and Giardia can be shed by livestock and domestic animals species, ${ }^{13}$ making it essential to account for animal host sources and their proximity to water sources. Human open defecation which remains widespread in rural India, ${ }^{1}$ and postdefecation anal cleansing in surface water bodies, present other nonpoint human sources and mechanisms of surface and groundwater contamination. Additionally, environmental processes, involving climate, hydrogeology, vegetation and soil for example, mediate Cryptosporidium and Giardia transport and distribution in the environment, ${ }^{14}$ while the type, quality, and condition of the water point (e.g., private and public, damaged vs intact) can have important impacts on water source quality. ${ }^{15}$ Prior studies have examined some of these processes, most often in isolation and using fecal indicators or tracers, for either surface or groundwater contamination, but rarely for both at the same time within the same setting. ${ }^{15-18}$ Joint evaluation of local sources and processes of fecal protozoa pathogen contamination for surface and groundwater together, accounting for both animal and human fecal pollution, multiple transport pathways, and environmental and other mediators, has not been undertaken. Such integrated study designs are needed to fully assess the public health implications of protozoal contamination and contributions of latrines as both a source and sink.

In this study, we investigate potential causes of previously reported Cryptosporidium and Giardia contamination observed concurrently in community surface and groundwater sources during two monsoon seasons in 60 villages in Puri District, Odisha, India. ${ }^{19}$ These villages were part of a large-scale cluster randomized controlled trial (the Odisha Sanitation Trial) of health impacts of improved household sanitation under a Total Sanitation Campaign intervention conducted in the district during $2011 .^{20}$ We develop a conceptual hierarchical model of local factors and processes causing protozoal contamination for Cryptosporidium and Giardia in surface and groundwater sources, and apply it to guide multivariable modeling to test relationships between protozoal contamination in a tested water source and water source characteristics, meteorological conditions prior to sampling, the density of nonpoint sources of human and animal fecal loading around each water source, including potential subsurface leaching from household pourflush latrine pits, and village-level socio-economic (SES) characteristics as proxies for other mediating factors.

\section{MATERIALS AND METHODS}

Study Site. Puri District is in a coastal region of India in Odisha state. Much of the groundwater is held in shallow unconfined and deeper semiconfined and confined aquifers, both primarily composed of unconsolidated gravel and sands. $^{21,22}$ Borehole surveys indicate confining layers are composed of clay. ${ }^{22}$ Unconfined aquifer depth is variable, but can reach $135 \mathrm{~m}$ below ground (blg), whereas confined aquifers can reach $602 \mathrm{~m} \mathrm{blg}{ }^{23}$ Other significant formations include porous laterites and jointed/faulted formations susceptible to weathering at depths of $20 \mathrm{~m} .^{21}$ The climate is tropical and characterized by wet summers (June to September) and dry winters (October to May), with much of the region experiencing annual flooding during the southwest monsoon from June to September.

Data and water samples for the 60 villages analyzed in this study were collected as part of the Odisha Sanitation Trial. Details of the Trial design, village selection, population characteristics, sanitation intervention and pour-flush pit latrine design and construction can be found elsewhere. ${ }^{6,24}$ Briefly, Trial villages had similar size, infrastructure, geography, and SES characteristics. Most households (62\%) lived below the Indian poverty line and owned livestock (59\%), with cattle an important host of zoonotic protozoa and the predominant species owned (56\%). Access to improved drinking water sources in the form of government-installed (deep) or private (shallow) tubewells was high (82\%). Deep tubewells (DTWs) were fitted with India Mark II style handpumps (maximum lift: $50 \mathrm{~m}$ ), shallow tubewells (STWs) had No. 6 style handpumps (maximum lift: $7 \mathrm{~m}$ ) and both were expected to be fully cased. ${ }^{25}$ Public ponds were used for daily hygiene activities by more than $50 \%$ of households. Household functional latrine coverage across study villages in February 2013 was 24\%. Government subsidized pour-flush latrines had a single circular leach pit of $\sim 1 \mathrm{~m}$ diameter, installed at ground level, extending $\sim 1 \mathrm{~m}$ deep. ${ }^{6}$ Self-financed pour-flush latrines were similar, except with deeper pits $(1-2 \mathrm{~m})$, or two in series. During the monsoon season in some areas of Puri District, pits may come in contact with the water table. ${ }^{21}$ See Supporting Information (SI), Figure S1, map of villages.

Protozoal Contamination of Community Water Sources. We previously reported results of testing six water sources in each village on a single day for Cryptosporidium and Giardia, comprising two public ponds, and two each of DTWs and STWs (when present), and protozoal shedding rates among humans, livestock and domestic animals in the region. ${ }^{19}$ Each source was sampled once in either 2012 or 2013 between June and August. Samples were collected during the morning ( $8 \mathrm{am}$ to $11 \mathrm{am}$ ) and GPS location and site observations 


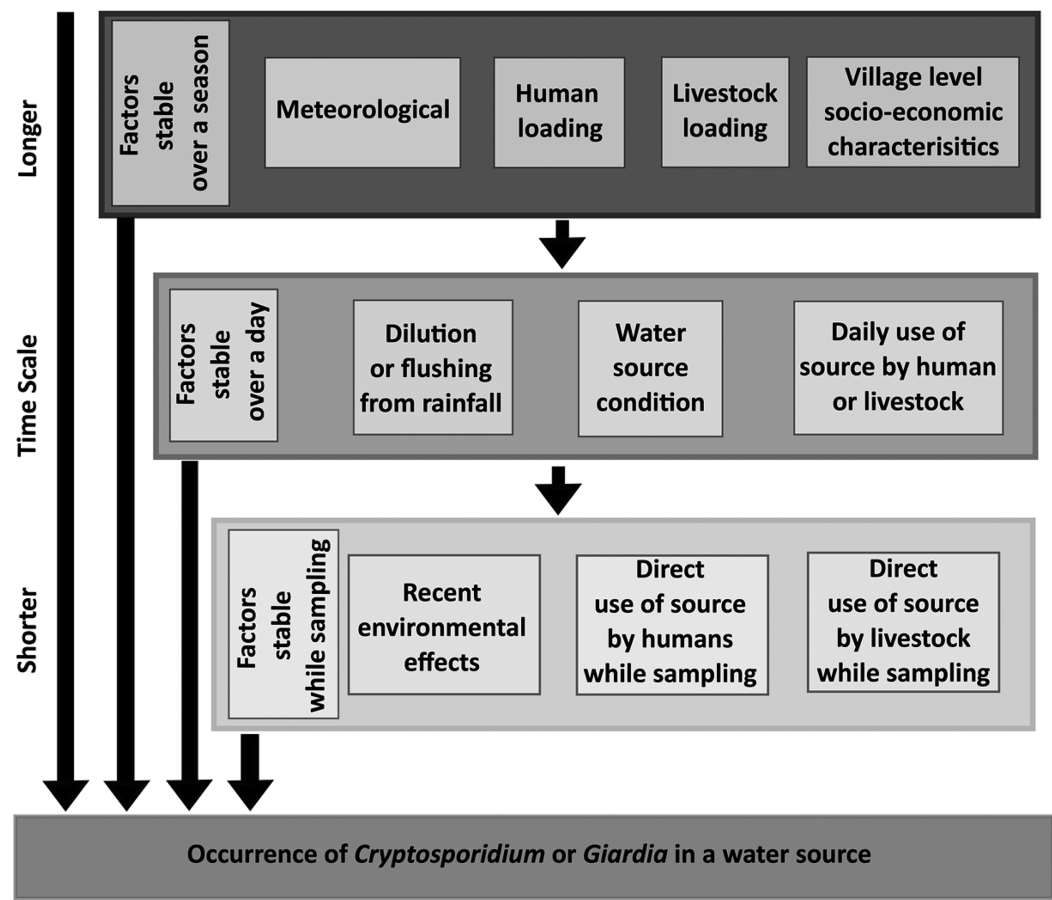

Figure 1. Conceptual model of multilevel factors involved in Cryptosporidium and Giardia contamination of community water sources. The three large boxes group factors hierarchically based of their time scale or temporal stability. Smaller boxes indicate factors involved at each time scale. Arrows indicate direct and indirect associations/causality between factors at different time scales and the outcome (e.g., level of open defecators in a village has an effect on the local uses of ponds, which in turn has an effect on the direct observations of human uses at a pond).

recorded. Cryptosporidium was detected in $37 \%, 14 \%$, and $5 \%$, respectively, of ponds $(n=94)$, DTWs $(n=110)$, and STWs $(n$ $=96$ ) and Giardia was detected in $74 \%, 12 \%$, and $17 \%$ of sources, respectively. ${ }^{19}$ See SI, section S1, for water processing details and SI, Table S1 for pathogen concentrations.

Conceptual Model of Local Sources and Mechanisms of Protozoal Contamination. We developed a conceptual model of multilevel factors involved in Cryptosporidium and Giardia contamination of community ponds and tubewells (Figure 1) to aid investigation. Levels represent different timescales of effects. Factors are categorized as meteorological, loading from local human and animal sources of fecal protozoa, water source-specific characteristics, or village-level SES characteristics. The top-level outlines factors that remain essentially constant within each sampling season (i.e., 2012 or 2013), such as village SES characteristics, annual climatic pattern, and village-level population of host animals, open defecators, latrines and latrine users. Factors in the second level are those that vary during the sampling season and affect dayto-day pollution levels, such as seasonal cumulative rainfall, recent rain, or an extreme event. The lowest level represents factors that can vary hour-to-hour and affect pollution levels at the time of sample collection, such as number of people using the site. Using the conceptual model we identified predictor variables from data sets collected as part of the Odisha Sanitation Trial and available meteorological data.

Cryptosporidium and Giardia from humans and from host species of domestic livestock in each village were considered, accounting for the most common livestock host species in Puri District (cattle, buffalo, goat, and sheep). ${ }^{19}$ Two local processes by which protozoal pathogens shed in human feces can contaminate a pond are overland flow from nearby open defecation fields and directly by people anal cleansing and bathing in ponds after defecation. People using the pond at the time of sampling could also stir up settled microorganisms. Processes by which local human feces can contaminate tubewell groundwater are through leaching and groundwater transport from nearby latrine pits and from direct infiltration of aboveground contaminated water at the tubewell head via a damaged well pad (platform) or inadequate seal. Similar to human fecal inputs, unmanaged livestock feces can reach ponds via overland flow and directly if animals enter them and can reach tubewell groundwater via direct surface infiltration at the well head if improperly sealed or damaged. Weather conditions and events are presumed to mediate the impacts of human and livestock fecal pollution sources on pond and tubewell contamination, through mechanisms such as flushing or dilution from rainfall or removal by ultraviolet decay. SES factors can also influence and mediate impacts of human and livestock sources as SES groups may differ in their health status, affecting pathogen shedding rates, or levels of access to improved sanitation and private water sources, affecting practices at ponds and public tubewells, for example.

Meteorological Factors. We obtained rainfall data $(\mathrm{mm}$ day $^{-1}$ ) from four weather stations in Puri District beginning June 1 (historical start of monsoon in Odisha is June 10th) for 2012 and 2013. To estimate rainfall in each village, we used the Thiessen polygon method as implemented in ArcGIS, version 10.2 (ESRI). The following rainfall variables were compiled and considered in analyses: cumulative seasonal rainfall from June 1 until the day prior to sampling; occurrence of any rainfall and of an extreme daily precipitation event during the 1,2, and 3 days prior to sampling. An extreme daily event was defined as rainfall exceeding the 90th percentile of daily totals between June and August in 2012 and 2013 (i.e., $>4 \mathrm{~cm} \mathrm{day}^{-1}$ ). Variables were also developed for other meteorological factors from daily data from a regional station (see SI, Tables S2-4). 


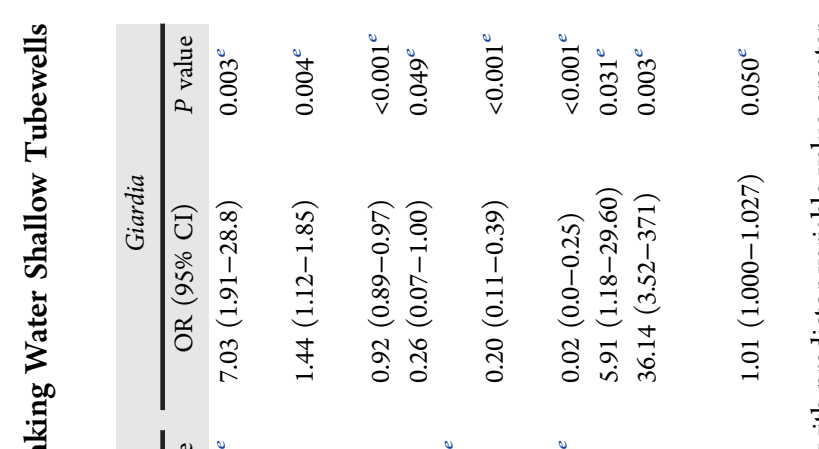

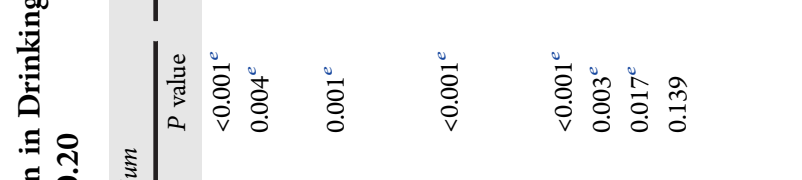

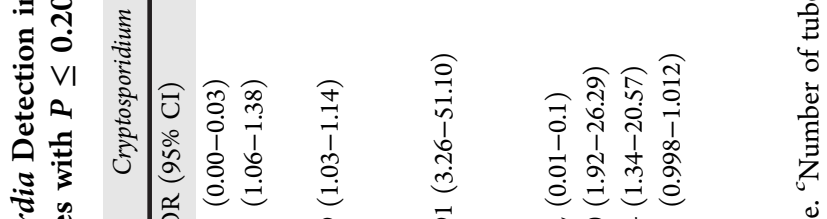

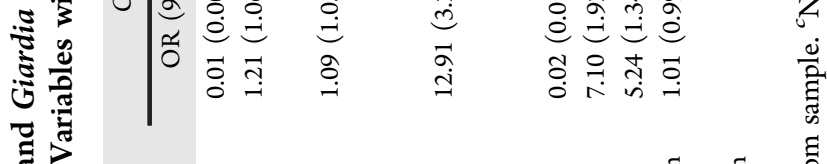

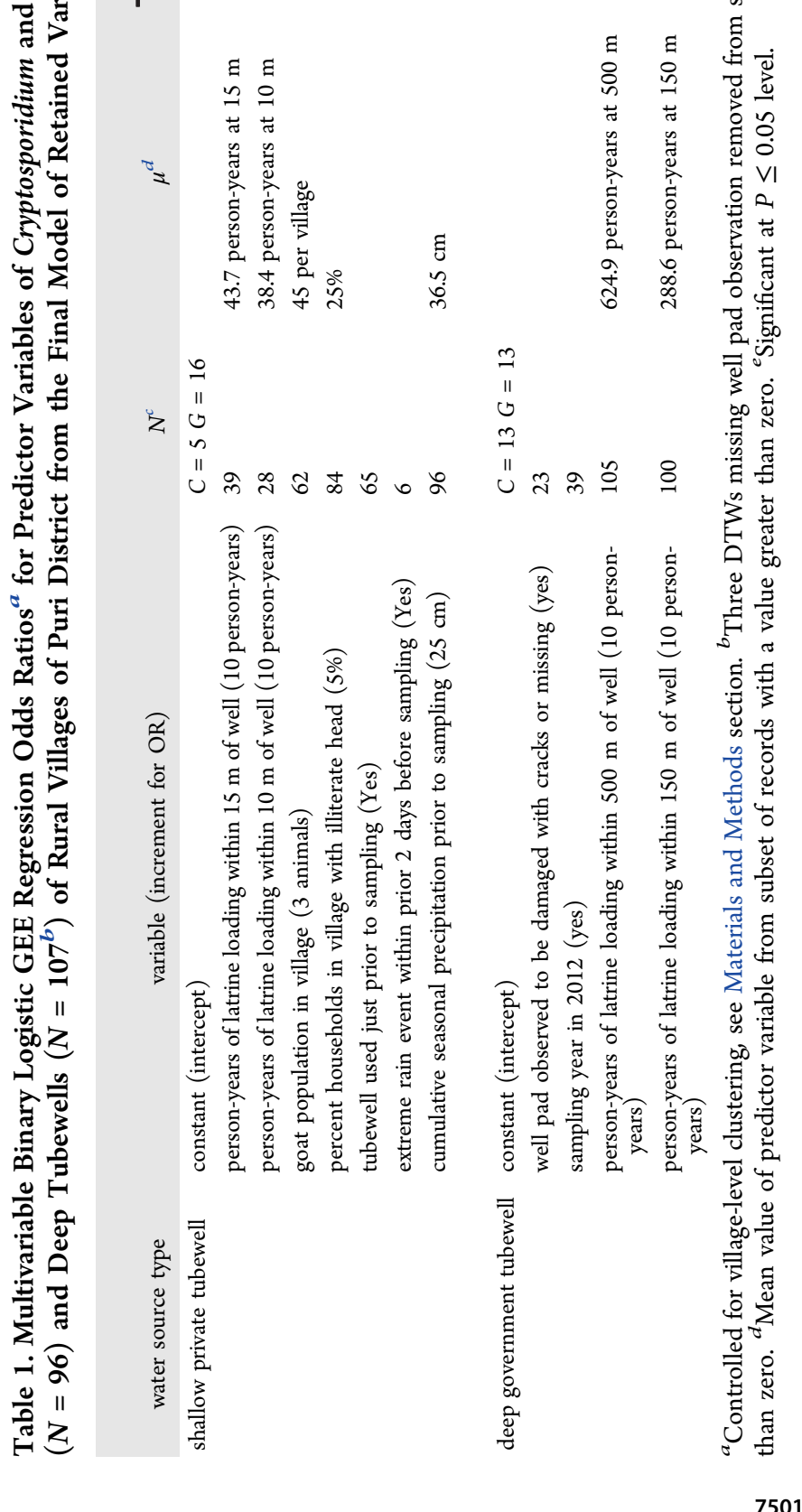


Table 2. Multivariable Proportional Odds Cumulative Logistic GEE Regression Odds Ratios ${ }^{a}$ for Predictor Variables of Cryptosporidium and Giardia Oocyst/Cyst Log10 Concentration $\left(20 \mathrm{~L}^{-1}\right)$ Level in Public Ponds $(N=94)$ of Rural Villages of Puri District from the Final Model of Retained Variables Significant at $P \leq 0.20$

\begin{tabular}{|c|c|c|c|c|c|c|}
\hline \multirow[b]{2}{*}{ variable (increment for OR) } & \multirow[b]{2}{*}{$N^{b}$} & \multirow[b]{2}{*}{$\mu^{c}$} & \multicolumn{2}{|c|}{ Cryptosporidium } & \multicolumn{2}{|l|}{ Giardia } \\
\hline & & & OR $(95 \% \mathrm{CI})$ & $P$ value & OR $(95 \% \mathrm{CI})$ & $P$ value \\
\hline sampling year in 2012 (Yes) & 35 & & $2.91(1.20-7.05)$ & $0.018^{d}$ & & \\
\hline open defecators living within $50 \mathrm{~m}$ of pond (6 people) & 43 & 28 people in $50 \mathrm{~m}$ & $1.13(1.02-1.26)$ & $0.026^{d}$ & & \\
\hline buffalo population in village (three animals) & 12 & 16 animals per village & & & $0.84(0.70-1.01)$ & 0.064 \\
\hline sheep population in village (three animals) & 45 & 22 animals per village & $1.06(1.01-1.12)$ & $0.020^{d}$ & & \\
\hline cattle observed at site while sampling (yes) & 3 & & $5.33(0.65-43.50)$ & 0.118 & & \\
\hline percent households in village with illiterate head (5\%) & 83 & $23 \%$ & & & $1.22(1.06-1.42)$ & $0.006^{d}$ \\
\hline cattlesheds within $200 \mathrm{~m}$ of pond ( 5 sheds) & 85 & 31 cattlesheds in $200 \mathrm{~m}$ & & & $1.06(0.99-1.13)$ & 0.087 \\
\hline rain occurrence within 2 days prior to sampling (yes) & 74 & & $5.38(1.25-23.21)$ & $0.024^{d}$ & & \\
\hline cumulative seasonal precipitation prior to sampling $(25 \mathrm{~cm})$ & 94 & $40.9 \mathrm{~cm}$ & & & $0.97(0.92-1.01)$ & 0.111 \\
\hline
\end{tabular}

${ }^{a}$ Controlled for village-level clustering, see Materials and Methods section. ${ }^{b}$ Number of ponds with predictor variable value greater than zero. ${ }^{c}$ Mean value of predictor variable from subset of records with a value greater than zero. ${ }^{d}$ Significant at the $P \leq 0.05$ level.

Human and Animal Fecal Loading Factors. A villagewide census and mapping of the location of each household and the sludge pit of each pour-flush latrine was conducted between December 2012 and February 2013 as previously described. ${ }^{20}$ During the census the following were collected: number of members of each household, whether the household had a cattleshed at/near the house, whether they owned a functional latrine, the household members using the latrine, and the age of the latrine. Because latrine use by those with household access in the region is suboptimal, ${ }^{26}$ to account for potentially large differences in loading rates of each census latrine in a village, we used reported number of users and age of each household latrine at the time of the census relative to the village's water sampling date to calculate the number of person-years of latrine use as an estimate for fecal loading at the time of water source sampling for each latrine pit (details in SI, section S3).

Using ArcGIS, version 10.2 (ESRI), the numbers of households, cattlesheds, and latrines pits around each tested water source, within a series of increasing buffer distances from the source, were counted (SI, Figure S4). Calculations were made at $5 \mathrm{~m}$ intervals from $0-50$ and $50 \mathrm{~m}$ intervals from $50-$ $200 \mathrm{~m}$, followed by a single buffer at $500 \mathrm{~m}$. Using extracted data at each buffer distance combined with village census data, the number of open defecators (associated with each household location), and person-years of latrine use (associated with each latrine pit location) were calculated (see SI, sections S3 and 4).

Using baseline data on animal ownership from a representative sample of households in each Trial village, ${ }^{24}$ we estimated village livestock populations from the average number of animals owned by species per baseline household and the total number of census households.

Socio-Economic Factors. Trial baseline data was also used to estimate the following village SES characteristics: (1) illiteracy rate among household heads, (2) fraction of households belonging to a scheduled caste, and (3) fraction of households self-reporting ownership of a poverty ration card (i.e., living below the Indian poverty line) as indicators of health status and behavioral factors.

Water Source Characteristics. Characteristics and observations recorded when sampling each water source and considered in the analysis were number of people (by age category and gender) and of livestock (by species) at the site, types of uses of the water source, condition of the tubewell pad (intact, cracked, or missing), and color of the water (clear and not clear).
Statistical Modeling Approach. We developed separate multivariable models of protozoa contamination for Cryptosporidium and Giardia in each water source type to account for different transport characteristics, sources, shedding rates, and survival of each microorganism, and different pathways involved in contamination of each water source type. To build our statistical models, we started with univariable analysis (i.e., one predictor variable) (see lists of predictors, SI, Tables S2-16). Initial multivariable models were constructed by including predictor variables with a $P$-value $\leq 0.2$ from univariable results. When greater than one predictor variable representing the same factor qualified for inclusion, the one with the smallest $P$-value was chosen, except for fecal loading spatial variables, where both a near $(<100 \mathrm{~m})$ and far $(\geq 100 \mathrm{~m})$ distance were included. We then used a backward selection approach ${ }^{27}$ and sequentially dropped each predictor variable with a $P$-value $>0.2$, starting with the variable with the largest $P$-value, to produce a final multivariable model with all variable $P$-values $\leq 0.2$. We accounted for village clustering in final models using general estimating equations (GEE). ${ }^{28}$ Statistical analyses were performed using SAS software, version 9.4 (SAS Institute Inc.).

Models of Pond Contamination. Prevalence of protozoa contamination of ponds was high and oocyst/cyst concentrations varied by up to 5 orders of magnitude, thus pond contamination was modeled as concentration level in univariable and multivariable modeling using GEE for proportional odds cumulative logit regression (also known as ordered logistic regression). ${ }^{29}$ Cryptosporidium and Giardia concentrations (oocysts/cysts $20 \mathrm{~L}^{-1}$ ) were converted to $\log 10$ levels (i.e., $<1$ parasite $=0 ; 1-10=1 ; 11-100=2$; so on to 4 ). Nondetect samples were assigned a level of zero. Adjusted odds ratios (OR) were calculated to estimate the marginal likelihood of one log-level higher concentration from a defined change in each predictor variable.

Models of Tubewell Contamination. Cryptosporidium and Giardia in DTWs and STWs were modeled as binary (presence/absence) outcomes due to their much lower prevalence and low concentrations and because tubewells are used for drinking. GEE for logistic regression was used. Adjusted OR from the final model indicate the marginal likelihood of tubewell protozoa contamination for a defined change in each predictor variable.

Predicted Effects of Full Latrine Coverage. We projected future densities of person-years of latrine loading (for the 2013 population density) at critical distances around 
Table 3. Predicted Impacts ${ }^{a}$ of Full Latrine Coverage on Protozoa Contamination of Ponds and Tubewells in Study Communities by 2017 and 2022, Compared to 2012-2013 Observed Rates

\begin{tabular}{|c|c|c|c|c|c|c|c|c|}
\hline \multirow[b]{2}{*}{$\begin{array}{l}\text { fecal protozoa in water } \\
\text { source }\end{array}$} & \multirow[b]{2}{*}{$\begin{array}{l}\text { critical } \\
\text { distance }\end{array}$} & \multicolumn{3}{|c|}{$\begin{array}{l}\text { TWs: person-years of latrine use } \\
\text { Ponds: people open defecating }\end{array}$} & \multicolumn{4}{|c|}{ prevalence } \\
\hline & & $\begin{array}{c}2013 \\
\text { observed }\end{array}$ & $\begin{array}{c}2017 \\
\text { projected }\end{array}$ & $\begin{array}{c}2022 \\
\text { projected }\end{array}$ & $\begin{array}{c}2013 \\
\text { observed }\end{array}$ & $\begin{array}{c}2017 \\
\text { predicted }\end{array}$ & $\begin{array}{c}2022 \\
\text { predicted }\end{array}$ & $\begin{array}{c}\text { ratio } \\
2022 / 2013\end{array}$ \\
\hline Cryptosporidium in STWs & $<15 \mathrm{~m}$ & 17.8 & 43.3 & 105.4 & $5 \%$ & $9 \%$ & $20 \%$ & 4.1 \\
\hline Giardia in STWs & $<10 \mathrm{~m}$ & 11.2 & 23.9 & 51.2 & $17 \%$ & $23 \%$ & $32 \%$ & 1.9 \\
\hline protozoa in STWs (either) ${ }^{b}$ & & & & & $19 \%$ & $29 \%$ & $46 \%$ & 2.4 \\
\hline Cryptosporidium in DTWs & $<500 \mathrm{~m}$ & 594 & 1493 & 3972 & $12 \%$ & $17 \%$ & $35 \%$ & 2.9 \\
\hline Giardia in DTWs & $<150 \mathrm{~m}$ & 266 & 736 & 2103 & $12 \%$ & $17 \%$ & $37 \%$ & 3.1 \\
\hline protozoa in DTWs (either) ${ }^{b}$ & & & & & $17 \%$ & $31 \%$ & $59 \%$ & 3.5 \\
\hline \multicolumn{9}{|l|}{ Cryptosporidium in Ponds } \\
\hline - (any) & $<50 \mathrm{~m}$ & 13 & 0 & 0 & $37 \%$ & $31 \%$ & $31 \%$ & 0.84 \\
\hline - $\left(>10020 \mathrm{~L}^{-1}\right)$ & & & & & $15 \%$ & $11 \%$ & $11 \%$ & 0.73 \\
\hline
\end{tabular}

${ }^{a}$ Calculated using predicted probabilities from multivariable models in Tables 1 and 2 for projected full latrine use (for tubewells) and elimination of open defecation rates (for ponds) at critical distances around each sampled water source in study communities, by 2017, and at end of Total Sanitation for All Campaign (2022). ${ }^{b}$ Predicted probability of either Cryptosporidium or Giardia contamination estimated by summing the predicted detection probability of each protozoa at a given water source.

each sampled surface and groundwater source in study communities and used these with final multivariable models to estimate the impacts on water source protozoa contamination of $100 \%$ pour-flush latrine usage in each study community by 2017 (the Government of India's target) and at the end of the Total Sanitation for All Campaign (2022). All other variables were held constant (see details, SI, section S6).

\section{RESULTS}

Predictors of Cryptosporidium and Giardia contamination and their adjusted OR and $P$-values in the final GEE regression models for DTWs and STWs are shown in Table 1 and for public ponds in Table 2 .

Factors Associated with Protozoa in Groundwater from Shallow and Deep Tubewells. Increased risk of protozoa detection in STWs was significantly correlated with human loading into nearby latrine pits: 10 more person-years of latrine loading within $15 \mathrm{~m}$ of a STW increased the odds of detecting Cryptosporidium by $21 \%$ (95\% OR: 1.06-1.38) and, when occurring within $10 \mathrm{~m}$, increased the odds of detecting Giardia by $44 \%$ (95\% OR: 1.12-1.85). Weaker evidence for latrine leaching effects on DTWs was also found. Each 10 person-years more of latrine loading within $500 \mathrm{~m}$ increased the odds of Cryptosporidium detection in a DTW by $1 \%(P=$ $0.139)$, while the same increase within $150 \mathrm{~m}$ increased the odds of Giardia detection by $1 \%(P=0.050)$. Only Giardia detection in STWs was associated with any village-level SES characteristics. A 5-percentage point increase in the proportion of illiterate household heads decreased the odds of detecting Giardia by $8 \%$ (95\% OR: $0.89-0.97$ ).

Some limited evidence of livestock sources of protozoa contamination of tubewells was found. Specifically, Cryptosporidium in STWs was positively associated with the goat population $(\mathrm{OR}=1.09$, 95\% OR: 1.03-1.14, per three additional goats). No other associations were found between protozoa in shallow or deep tubewells and livestock animal loading variables.

Both protozoa were significantly more likely to be detected in groundwater from a DTW with a damaged well pad, at 7.10 times (95\% OR: 1.92-20.57) for Cryptosporidium and 5.91 times (95\% OR: 1.18-29.60) for Giardia, than from one with an intact pad. We did not find statistically greater odds of detecting protozoal pathogens in a damaged STW, however, STWs with a damaged pad had higher detection frequencies of both protozoa (SI, Table S19). STWs which were being used immediately prior to sampling had significantly lower odds of detecting Giardia (0.26, 95\%OR: 0.07-1.00).

In STWs Cryptosporidium was significantly more likely to be detected within 2 days after an extreme rain event $(\mathrm{OR}=12.91$, 95\% OR: 3.26-51.10), while Giardia was significantly less likely to be detected as seasonal rainfall increased $(\mathrm{OR}=0.20$, 95\% OR: $0.11-0.39$, each $25 \mathrm{~cm}$ of seasonal rainfall prior to sampling). No rainfall variables were associated with DTW contamination, however, both protozoa were detected in DTWs significantly more often in 2012 than in 2013 (Cryptosporidium OR $=5.24$, 95\% OR: 1.34-20.57; Giardia OR $=36.14$, 95\% OR: 3.52-371). Protozoa detection in STWs was unassociated with year. We found no other meteorological associations.

Factors Associated with Protozoa in Community Ponds. Protozoa concentration levels in ponds were positively associated with the number of people practicing open defecation living within $50 \mathrm{~m}$ of the pond but not at distances beyond that, and with village illiteracy rates, recent use by cattle, populations of specific species of livestock, sampling year, and antecedent rainfall patterns. Each six additional people (average household size) practicing open defecation and living within $50 \mathrm{~m}$ significantly increased the odds of a pond having one log (10 times) more Cryptosporidium oocysts $\left(20 \mathrm{~L}^{-1}\right)$ by 1.13 (95\% OR: $1.02-1.26$ ) while each additional 5\% of households with an illiterate head significantly increased the odds of one log more Giardia concentration by 1.22 (95\% OR: 1.06-1.42). Neither signs of regular or recent human use (e.g., paths) nor human use observed at a pond prior to sampling were associated with increased protozoa levels.

When cattle were observed at a pond prior to sampling, we found some evidence that the Cryptosporidium concentration was likely to be 10 times higher than when cattle were absent $(\mathrm{OR}=5.33$, 95\% OR: $0.65-43.50)$ and when there were more cattlesheds within $200 \mathrm{~m}$ of a pond, the Giardia concentration was likely to be higher $(\mathrm{OR}=1.06,95 \%$ OR: $0.99-1.13$, each five additional cattlesheds). We also observed associations between a village's sheep and buffalo populations and pond parasite levels. Three additional sheep significantly increased 
the likelihood of a higher Cryptosporidium level $(\mathrm{OR}=1.06$, 95\% OR: 1.01-1.12), while three additional buffalo (mean number per buffalo-owning household) had a nearly significant protective effect on Giardia concentrations ( $\mathrm{OR}=0.84,95 \%$ OR: $0.70-1.01)$.

Conceptually, rainfall could either flush oocysts/cysts into ponds through overland flow or dilute concentrations by flooding or filling ponds; our analyses showed evidence of the effects of overland flow/flushing on Cryptosporidium concentrations and of dilution on Giardia concentrations in ponds, consistent with the results for STWs. When rainfall occurred anytime during the 2 days prior to sampling, a pond's Cryptosporidium concentration was 5.38 times (95\% OR: 1.25-23.21) more likely to be an order of magnitude higher than when it had been dry, while each additional $25 \mathrm{~cm}$ of seasonal rainfall increased the probability of a pond's Giardia concentration being a log 10 level lower by 3\% (95\% OR: $0.92-$ 1.01). Lastly, as found for Cryptosporidium in DTWs, ponds in 2012 were significantly more likely to have higher Cryptosporidium concentration levels than those sampled in 2013 (OR = 2.91, 95\% OR: 1.20-7.05) all other effects constant. No other associations with meteorological factors were detected.

Predicted Protozoa Contamination under Full Latrine Coverage. Model-derived predictions of local surface and groundwater source contamination rates for each protozoa during the monsoon season are shown in Table 3 for projected latrine loading densities under 100\% latrine coverage by 2017 and through 2022. Under projected full coverage, small predicted reductions occur in the pond contamination rate for Cryptosporidium (16\%) concurrently with large predicted increases in shallow and deep tubewell groundwater contamination for each protozoa (1.9-4.1 times by 2022) over baseline 2012-13 rates, with the greatest increases expected for Cryptosporidium contamination in STWs.

\section{DISCUSSION}

We investigated multiple sources and mechanisms for Cryptosporidium and Giardia contamination of community tubewells and ponds across 60 villages in a coastal district in rural India including pour-flush household latrines as a potential protozoa source (or sink, via reduced open defecation). Multivariable modeling showed that protozoa contamination of local groundwater used for drinking was positively correlated with the density of human fecal loading into latrine pits, literacy rates, livestock populations, damaged tubewells, antecedent rainfall patterns and annual variability. Levels of contamination of local ponds used daily for bathing and hygiene were positively correlated with the number of residents practicing open defecation nearby, illiteracy rates, livestock populations, antecedent rainfall patterns and annual variability.

Latrine Effects. Previous observational and experimental studies have identified bacteria and virus groundwater contamination from latrines up to 25 and $50 \mathrm{~m}$ away, respectively. ${ }^{5}$ This is the first study to examine latrines simultaneously as a source and sink of environmental protozoa contamination. We found strong evidence of protozoa contamination of shallow groundwater from pour-flush latrines within $15 \mathrm{~m}$ and some limited evidence for deeper groundwater contamination from pour-flush latrines up to $500 \mathrm{~m}$ away. Shallow tubewells in the study area draw water from $<7 \mathrm{~m} \mathrm{bgl}$ and during the monsoon period the water table can rise as high as $0-2 \mathrm{~m} \mathrm{bgl},{ }^{21}$ making a hydraulic connection between latrine pits $(\sim 1 \mathrm{~m} \mathrm{bgl})$ and shallow groundwater likely. Intermittent hydraulic connection between latrines pits and groundwater, persistence of protozoa in water and soil, and potential for long-term protozoal transport support our finding of nearby latrine loading as an important risk for shallow groundwater protozoal contamination in this setting.

Pathogen transport in deeper groundwater at distances $>100$ $\mathrm{m}$ from a pollution source, as detected in our study, is less often examined. ${ }^{5,30}$ Waterborne outbreaks of cryptosporidiosis and giardiasis in North America linked to use of groundwater for drinking, however, provide evidence of deep groundwater protozoal contamination. ${ }^{31}$ Further evidence for the plausibility of deep groundwater contamination at distance $>100 \mathrm{~m}$ comes from a study of artificial groundwater recharge using treated wastewater in which both Cryptosporidium and Giardia were detected in groundwater at 320 and $500 \mathrm{~m}$, respectively, from recharge zones in fractured limestone. ${ }^{32}$ The mostly porous gravels and sand aquifers in our study area ${ }^{21}$ may provide sufficient pore space for protozoal transport, supporting the limited evidence $(0.05<P<0.14)$ we also found for local latrines as a source of deeper groundwater protozoal contamination.

Research on overland transport of protozoa shows a clear connection between animal fecal loading on land and contamination of nearby surface water, with factors such as slope, soil type, and vegetation density affecting transport. ${ }^{33,34}$ While human fecal loading on land also poses risks for protozoa contamination of nearby surface water, the circumstances and magnitude of benefits on surface water protozoa contamination from ending open defecation in countries where the practice remains prevalent have not been examined. We observed a significant relationship between the number of people living nearby a pond who practiced open defecation (within $50 \mathrm{~m}$, not beyond) and the pond Cryptosporidium concentration level. Genotyping of contaminated pond samples in this and another similar rural setting in Bangladesh identified Cryptosporidium hominis (human-specific genotype) but not other genotypes. ${ }^{19,35}$ Together, these findings suggest that promoting latrine use by people living nearby, and protective buffers around local water bodies, could reduce human host-specific Cryptosporidium pond contamination in this setting. Reduced Cryptosporidium contamination of ponds from increased latrine uptake predicted in this setting is, however, overshadowed by the large expected negative effects of increased uptake on protozoal contamination of local groundwater drinking sources (Table 3).

Livestock. Village sheep, goats, and cattle appear to be important local animal host contributors of Cryptosporidium contamination detected in community water sources in this setting, while cattle in particular appear to contribute to Giardia contamination. Unexpectedly, we observed a trend where villages with more buffalo had lower levels of pond Giardia contamination. We know of no biological explanation for the association, which may be confounded. Among livestock and domestic animal populations in India and globally, cattle are frequently infected with Cryptosporidium and Giardia. ${ }^{36-39}$ However, evidence from a systematic review and other studies of zoonotic disease transmission from livestock and cattle to humans in this and similar settings is mixed. ${ }^{40-42}$ Overall, the public health significance of exposure to protozoa shed by livestock and domestic animals is case-specific since these animals can shed zoonotic protozoa, infectious to humans, as well as host-specific genotypes. ${ }^{13}$ 
Rainfall and Other Meteorological Factors. Rainfall effects on protozoal surface water contamination have been studied, ${ }^{43,44}$ but few have considered human and nonhuman protozoa sources and examined impacts on surface and groundwater contamination. Over short time scales (i.e., within the monsoon season) our results indicate that rainfall is an important mediator of local environmental sources of human and animal fecal protozoal loading on contamination of ponds and shallow groundwater. Positive associations between rainfall events (i.e., $>$ 90th and $>80$ th percentile of monthly rainfall) and waterborne disease outbreaks and fecal contamination, have been previously reported. ${ }^{18,45,46}$ In our modeling of STW and pond contamination, rainfall variables associated with Cryptosporidium contamination were different from those associated with Giardia contamination, implying different physical processes of importance. Cryptosporidium in STWs and higher concentrations in ponds were more likely after a recent event (within 2 days) suggesting short-term cyclical processes of environmental loading and accumulation followed by contaminant flushing and transport pulses. On the other hand, Giardia detection in STWs and concentration levels in ponds were negatively associated with increasing cumulative rainfall (monsoon season), suggesting dilution of widespread background contamination. These hypothesized contrasting environmental processes are consistent with finding Giardia to be much more ubiquitous (higher endemic infection rates and orders of magnitude more parasites shed per host) than Cryptosporidium in this setting and a similar environment. ${ }^{19,35}$

After controlling for within-season shorter time-scale meteorological effects, sampling year (2012 vs. 2013), a potential proxy for longer time-scale variability, remained associated with significant differences in Cryptosporidium and Giardia contamination in DTWs, but not STWs, and Cryptosporidium in ponds. Characteristics and population-level patterns of infection for each protozoa, ${ }^{47-49}$ as well as larger scale climatic and hydrogeological conditions for which we were unable to account, may have played a role.

Village Socio-Economic Factors. Village illiteracy rates were the strongest predictor of increased Giardia contamination levels in ponds, while at the same time were associated with lower Giardia risk in STWs. Livestock ownership in our study population at baseline was nearly equal among illiterate and literate households ( $57 \%$ vs $60 \%$ ), however, latrine ownership was greater among literate households $(\sim 13 \%)$ compared to illiterate households $(\sim 3 \%)$ and more illiterate households bathed at ponds (72\%) compared to literate households (55\%). Given similar animal ownership but lower latrine use (i.e., higher open defecation) and higher pond bathing rates among illiterate vs. literate households, the link between illiteracy and increased pond Giardia contamination would seem to point to a human source behind elevated Giardia levels in ponds, that is, from higher overall rates of open defecation and of anal cleansing and bathing in ponds in villages with higher illiteracy rates. The protective effect of illiteracy on STW contamination may arise similarly from the lower overall village-wide latrine uptake rate and its associated loading into shallow groundwater, or may be confounded.

Water Source Characteristics. Wellhead protection is critical for preserving groundwater quality, ${ }^{50}$ and poor well condition has previously been linked to well water fecal bacterial contamination. ${ }^{15,17,46,51,52}$ Our finding that DTWs with damaged pads (cracked or missing) were significantly associated with detectable levels of Cryptosporidium and
Giardia, extends this link to larger protozoal organisms in low-income settings. Interestingly, we did not find a significant increased risk of contamination in STWs with well pad damage, possibly because private household STWs are used less intensely than public DTWs.

STWs used immediately prior to sampling were significantly less likely to have detectable levels of Giardia than those that had been idle. The sample collected from such STWs may have included a larger volume of more distant and deeper cleaner groundwater, which may have diluted the impact from nearby latrine leaching. We did not observe an effect on Cryptosporidium, possibly because the subsample of Cryptosporidiumpositive STWs was too small to detect an effect.

Limitations. Future studies examining water body contamination and fecal pollution sources in similar settings should consider the potential effects of fecal sources located outside defined study boundaries. Mapping in this analysis was limited to the point locations of local pollution sources in Odisha Sanitation Trial villages. We were thus unable to account for the possibility of unmapped villages having open defecator households, latrine pits or cattlesheds within the largest buffer distance $(500 \mathrm{~m})$ considered around community water sources. This limitation is likely to mainly affect our analyses of ponds, which were often located on the outskirts, rather than of tubewells, located within the village. We also relied on selfreport, which is subject to recall bias, ${ }^{53}$ for estimating usage rates and ages of latrines. Repeated sampling of each water source would have provided greater accuracy on protozoal prevalence and concentration levels in each source and allowed for more fully characterizing spatial and temporal variations in water source contamination than was possible in our staggered cross-sectional study design. However, because site visits for this study were randomized spatially across a relatively homogeneous geographic study area and temporally within the first 2-3 months of each monsoon season, and because study villages were similar in terms of size, types of water and sanitation infrastructure, SES characteristics, and economic activity, and all samples were collected in the morning hours, we do not foresee significant bias stemming from our single point sample design when used to estimate area-level associations within the context of monsoon season contamination patterns, as we have done here.

Better information on soils, weather, and hydrogeology, such as groundwater recharge zones and detailed lithology, would have allowed for better characterization of protozoal transport into each tubewell or pond, but was not available and beyond the scope of data collection for the Odisha Sanitation Trial. However, all study villages were within $\sim 50 \mathrm{~km}$ of each other, and the geology of the study region is defined primarily as a delta plane with predominant alluvium geological formation, ${ }^{21,22}$ reducing potential bias from these limitations. We cannot preclude the possibility that Cryptosporidium and Giardia detected in a tubewell sample could have come from a contaminated spout/mouth, however, we flushed each tubewell prior to sample collection for $\sim 30 \mathrm{~s}$ and then rinsed each $2 \mathrm{~L}$ sample bottle with tubewell water 3 times prior to filling to minimize this possibility. Our village-level SES variables are imprecise and subject to residual confounding from measurement error or miss-specification of a category. For example, beyond literacy status of the household head, educational attainment level may have improved the association between education status and water contamination. Finally, although our conceptual model represents causal relationships 
grounded in scientific literature, cross-sectional data and empirical modeling can only identify correlations and our sample size may be under-powered to detect some postulated associations. These limitations must be kept in mind when interpreting the associations we found between outcomes and predictor variables.

Policy and Public Health Implications. Further research and better guidelines are needed to ensure the protection of critical water sources used for drinking and to ensure household access to microbiologically safe protozoa-free drinking water in rural India. Based on our findings, guidelines would include repairing damaged deep tubewells to protect public groundwater drinking sources and placing pour-flush latrine pits in India at distances $>15 \mathrm{~m}$ from shallow tubewells used for drinking. However, these recommendations may be ineffective in areas like this where water tables can rise within $2 \mathrm{~m}$ of ground-level and given the marginal evidence for and plausibility of deeper groundwater contamination from latrine leaching densities at greater distances. Alternatively, changing the below-ground design of wet latrines may be needed to reduce or prevent leaching rates and associated pathogen loads, but these increase sanitation costs. In view of already widespread contamination of local water sources, anticipated rapid growth in latrine coverage, and difficulties achieving high compliance and effective use of household water treatment, ${ }^{54,55}$ centrally treated and reliable piped water supplies with house connections may be a better solution for ensuring safe drinking water in this setting.

\section{ASSOCIATED CONTENT}

\section{S Supporting Information}

The Supporting Information is available free of charge on the ACS Publications website at DOI: 10.1021/acs.est.5b05797.

Maps and all spatial and nonspatial variable data sets, sources, and descriptive statistics (PDF)

\section{AUTHOR INFORMATION}

\section{Corresponding Author}

*E-mail: mwjenkins@ucdavis.edu.

\section{Author Contributions}

M.J. and M.D. conceived of and designed the study with inputs from W.S. M.D. conducted the analyses with inputs from M.J. and W.P.S., and wrote the first and subsequent drafts with contributions of M.J. All authors contributed to interpretation of results and revisions of the final manuscript.

\section{Notes}

The authors declare no competing financial interest.

\section{REFERENCES}

(1) WHO. Unicef, Progress on Sanitation and Drinking Water: 2015 Update and MDG Assessment; World Health Organization: Geneva, 2015.

(2) Baldursson, S.; Karanis, P. Waterborne transmission of protozoan parasites: Review of worldwide outbreaks: An update 2004-2010. Water Res. 2011, 45 (20), 6603-6614.

(3) Kotloff, K. L.; Nataro, J. P.; Blackwelder, W. C.; Nasrin, D.; Farag, T. H.; Panchalingam, S.; Wu, Y.; Sow, S. O.; Sur, D.; Breiman, R. F. Burden and aetiology of diarrhoeal disease in infants and young children in developing countries (the Global Enteric Multicenter Study, GEMS): a prospective, case-control study. Lancet 2013, 382 (9888), 209-222.

(4) India, G. o. Nirmal Bharat: Total Sanitation for all. http://www. archive.india.gov.in/spotlight/spotlight_archive.php?id=92.
(5) Graham, J. P.; Polizzotto, M. L. Pit latrines and their impacts on groundwater quality: a systematic review. Environ. Health Perspect. 2013, 121 (5), 521-30.

(6) Ministry of Urban Development, New Delhi, India. Manual on Sewerage and Sewage Treatment. http://www.cmamp.com/CP/ FDocument/ManualonSewerageTreatment.pdf.

(7) Parker, A.; Carlier, I., National regulations on the safe distance between latrines and waterpoints. DEW Point, Dec 2009.

(8) Lawrence, A. R.; Macdonald, D. M. J.; Howard, A. G.; Barrett, M. H.; Pedley, S.; Ahmed, K. M.; Nalubega, M., Guidelines for assessing the risk to groundwater from on-site sanitation, British Geological Survey, Commissioned Report CR/01/1422001, 2001.

(9) Tufenkji, N.; Miller, G. F.; Ryan, J. N.; Harvey, R. W.; Elimelech, M. Transport of Cryptosporidium oocysts in porous media: Role of straining and physicochemical filtration. Environ. Sci. Technol. 2004, 38 (22), 5932-5938.

(10) Harter, T.; Wagner, S.; Atwill, E. R. Colloid transport and filtration of Cryptosporidium parvum in sandy soils and aquifer sediments. Environ. Sci. Technol. 2000, 34 (1), 62-70.

(11) Olson, M. E.; Goh, J.; Phillips, M.; Guselle, N.; McAllister, T. A. Giardia cyst and Cryptosporidium oocyst survival in water, soil, and cattle feces. Journal of Environmental Quality 1999, 28 (6), 1991-1996.

(12) Fayer, R.; Dubey, J. P.; Lindsay, D. S. Zoonotic protozoa: from land to sea. Trends Parasitol. 2004, 20 (11), 531-6.

(13) Xiao, L.; Fayer, R. Molecular characterisation of species and genotypes of Cryptosporidium and Giardia and assessment of zoonotic transmission. Int. J. Parasitol. 2008, 38 (11), 1239-55.

(14) Lal, A.; Baker, M. G.; Hales, S.; French, N. P. Potential effects of global environmental changes on cryptosporidiosis and giardiasis transmission. Trends Parasitol. 2013, 29 (2), 83-90.

(15) Sorensen, J. P. R.; Sadhu, A.; Sampath, G.; Sugden, S.; Gupta, S. D.; Lapworth, D. J.; Marchant, B. P.; Pedley, S. Are sanitation interventions a threat to drinking water supplies in rural India? An application of tryptophan-like fluorescence. Water Res. 2016, 88, 923932.

(16) Knappett, P. S.; Escamilla, V.; Layton, A.; McKay, L. D.; Emch, M.; Williams, D. E.; Huq, R.; Alam, J.; Farhana, L.; Mailloux, B. J.; Ferguson, A.; Sayler, G. S.; Ahmed, K. M.; van Geen, A. Impact of population and latrines on fecal contamination of ponds in rural Bangladesh. Sci. Total Environ. 2011, 409 (17), 3174-82.

(17) Knappett, P. S. K.; McKay, L. D.; Layton, A.; Williams, D. E.; Alam, M. J.; Mailloux, B. J.; Ferguson, A. S.; Culligan, P. J.; Serre, M. L.; Emch, M. Unsealed tubewells lead to increased fecal contamination of drinking water. J. Water Health 2012, 10 (4), 565-578.

(18) Wu, J.; Yunus, M.; Islam, M. S.; Emch, M. Influence of climate extremes and land use on fecal contamination of shallow tubewells in Bangladesh. Environ. Sci. Technol. 2016, 50, 2669.

(19) Daniels, M. E.; Shrivastava, A.; Smith, W. A.; Sahu, P.; Odagiri, M.; Misra, P. R.; Panigrahi, P.; Suar, M.; Clasen, T.; Jenkins, M. W. Cryptosporidium and Giardia in Humans, Domestic Animals, and Village Water Sources in Rural India. Am. J. Trop. Med. Hyg. 2015, 93, 15-0111.

(20) Clasen, T.; Boisson, S.; Routray, P.; Torondel, B.; Bell, M.; Cumming, O.; Ensink, J.; Freeman, M.; Jenkins, M.; Odagiri, M. Effectiveness of a rural sanitation programme on diarrhoea, soiltransmitted helminth infection, and child malnutrition in Odisha, India: a cluster-randomised trial. Lancet Glob Health 2014, 2, 645653.

(21) Kumar, L. T. Salient Features of Lithological Distribution and Feasibility Study of Water Resources in Coastal Aquifers of Puri, India. Int. J. Environ. Eng. Res. 2012, 1 (2), 60-69.

(22) Choudhury, A.; S. Sarkar, S.; Das, P. K.; Pati, G. C., Coastal Aquifers of Orissa - A Simplistic Overview. In workshop on water quality management in eastern region, India, CGWB, SE Region, Bhubaneswar2009; pp.24-39.

(23) Resources, M. o. W. Ground water information booklet Puri District, Orissa. http://www.cgwb.gov.in/District_Profile/Orissa/Puri. pdf (accessed March 2016). 
(24) Clasen, T.; Boisson, S.; Routray, P.; Cumming, O.; Jenkins, M.; Ensink, J. H.; Bell, M.; Freeman, M.; Peppin, S.; Schmidt, W.-P. The effect of improved rural sanitation on diarrhoea and helminth infection: design of a cluster-randomized trial in Orissa, India. Emerg Themes Epidemiol 2012, 9 (1), 7.

(25) WaterAid Handpumps: Techincal Brief. http://www.wateraid. org/ /media/Publications/Handpumps.pdf.

(26) Jenkins, M. W.; Freeman, M. C.; Routray, P. Measuring the Safety of Excreta Disposal Behavior in India with the New Safe San Index: Reliability, Validity and Utility. Int. J. Environ. Res. Public Health 2014, 11 (8), 8319-8346.

(27) Neefus, C. D.; Gotelli, N. J.; Ellison, A. M. A Primer of Ecological Statistics. In JSTOR 2004.

(28) Hanley, J. A.; Negassa, A.; Forrester, J. E. Statistical analysis of correlated data using generalized estimating equations: an orientation. Am. J. Epidemiol. 2003, 157 (4), 364-375.

(29) Agresti, A. Analysis of Ordinal Categorical Data; John Wiley \& Sons, 2010; Vol. 656

(30) Bradbury, K. R.; Borchardt, M. A.; Gotkowitz, M.; Spencer, S. K.; Zhu, J.; Hunt, R. J. Source and transport of human enteric viruses in deep municipal water supply wells. Environ. Sci. Technol. 2013, 47 (9), 4096-4103.

(31) Blackburn, B. G.; Craun, G. F.; Yoder, J. S.; Hill, V.; Calderon, R. L.; Chen, N.; Lee, S. H.; Levy, D. A.; Beach, M. J. Surveillance for waterborne-disease outbreaks associated with drinking water-United States, 2001-2002. MMWR Surveill Summ 2004, 53 (8), 23-45.

(32) Mantia, R. L.; Masciopinto, C.; Levantesi, C.; Tandoi, V. Fate and transport of faecal contamination microbial indicators, pathogenic protozoa and Campylobacter in the artificially recharged fractured aquifer of Salento, Italy. Water Sci. Technol. 2008, 57 (6), 849-856.

(33) Pachepsky, Y. A.; Sadeghi, A. M.; Bradford, S. A.; Shelton, D. R.; Guber, A. K.; Dao, T. Transport and fate of manure-borne pathogens: Modeling perspective. Agric. Water Manage 2006, 86 (1-2), 81-92.

(34) Atwill, E. R.; Hou, L.; Karle, B. M.; Harter, T.; Tate, K. W.; Dahlgren, R. A. Transport of Cryptosporidium parvum oocysts through vegetated buffer strips and estimated filtration efficiency. Appl. Environ. Microbiol. 2002, 68 (11), 5517-5527.

(35) Ehsan, A. M.; Geurden, T.; Casaert, S.; Parvin, S. M.; Islam, T. M.; Ahmed, U. M.; Levecke, B.; Vercruysse, J.; Claerebout, E. Assessment of zoonotic transmission of Giardia and Cryptosporidium between cattle and humans in rural villages in Bangladesh. PLoS One 2015, 10 (2), e0118239.

(36) Khan, S. M.; Debnath, C.; Pramanik, A. K.; Xiao, L.; Nozaki, T.; Ganguly, S. Molecular characterization and assessment of zoonotic transmission of Cryptosporidium from dairy cattle in West Bengal, India. Vet. Parasitol. 2010, 171 (1-2), 41-7.

(37) Khan, S. M.; Debnath, C.; Pramanik, A. K.; Xiao, L.; Nozaki, T.; Ganguly, S. Molecular evidence for zoonotic transmission of Giardia duodenalis among dairy farm workers in West Bengal, India. Vet. Parasitol. 2011, 178 (3-4), 342-5.

(38) Olson, M. E.; O’Handley, R. M.; Ralston, B. J.; McAllister, T. A.; Thompson, R. C. Update on Cryptosporidium and Giardia infections in cattle. Trends Parasitol. 2004, 20 (4), 185-91.

(39) Rakesh, R. L.; Banerjee, P. S.; Garg, R.; Maurya, P. S.; Kundu, K.; Jacob, S. S.; Raina, O. K., Genotyping of Cryptosporidium spp. isolated from young domestic ruminants in some targeted areas of India. Indian J. Ani. Sci. 2014, 84, (8).

(40) Zambrano, L. D.; Levy, K.; Menezes, N. P.; Freeman, M. C. Human diarrhea infections associated with domestic animal husbandry: a systematic review and meta-analysis. Trans. R. Soc. Trop. Med. Hyg. 2014, 108 (6), 313-325.

(41) Schmidt, W. P.; Boisson, S.; Routray, P.; Bell, M.; Cameron, M.; Torondel, B.; Clasen, T. Exposure to cows is not associated with diarrhoea or impaired child growth in rural Odisha, India: a cohort study. Epidemiol. Infect. 2016, 144, 1-11.

(42) Kattula, D.; Francis, M. R.; Kulinkina, A.; Sarkar, R.; Mohan, V. R.; Babji, S.; Ward, H. D.; Kang, G.; Balraj, V.; Naumova, E. N. Environmental predictors of diarrhoeal infection for rural and urban communities in south India in children and adults. Epidemiol. Infect. 2015, 143, 1-12.

(43) Young, I.; Smith, B. A.; Fazil, A. A systematic review and metaanalysis of the effects of extreme weather events and other weatherrelated variables on Cryptosporidium and Giardia in fresh surface waters. J. Water Health 2015, 13 (1), 1-17.

(44) Blaustein, R. A.; Pachepsky, Y. A.; Shelton, D. R.; Hill, R. L. Release and removal of microorganisms from land-deposited animal waste and animal manures: A review of data and models. Journal of environmental quality 2015, 44 (5), 1338-1354.

(45) Curriero, F. C.; Patz, J. A.; Rose, J. B.; Lele, S. The association between extreme precipitation and waterborne disease outbreaks in the United States, 1948-1994. Am. J. Public Health 2001, 91 (8), 1194-1199.

(46) Godfrey, S.; Timo, F.; Smith, M. Relationship between rainfall and microbiological contamination of shallow groundwater in Northern Mozambique. Water SA 2006, 31 (4), 609-614.

(47) Robertson, L. J.; Hanevik, K.; Escobedo, A. A.; Mørch, K.; Langeland, N. Giardiasis-why do the symptoms sometimes never stop? Trends Parasitol. 2010, 26 (2), 75-82.

(48) Mukherjee, A. K.; Chowdhury, P.; Bhattacharya, M. K.; Ghosh, M.; Rajendran, K.; Ganguly, S. Hospital-based surveillance of enteric parasites in Kolkata. BMC Res. Notes 2009, 2 (1), 110.

(49) Lal, A.; Hales, S.; French, N.; Baker, M. G. Seasonality in human zoonotic enteric diseases: a systematic review. PLoS One 2012, 7 (4), e31883.

(50) Schmoll, O.; Howard, G.; Chilton, J.; Chorus, I. Protecting groundwater for health: managing the quality of drinking-water sources. Water Intelligence Online 2013, 12, 9781780405810.

(51) Ye, B.; Yang, L.; Li, Y.; Wang, W.; Li, H. Water sources and their protection from the impact of microbial contamination in rural areas of Beijing, China. Int. J. Environ. Res. Public Health 2013, 10 (3), 879891.

(52) Howard, G.; Pedley, S.; Barrett, M.; Nalubega, M.; Johal, K. Risk factors contributing to microbiological contamination of shallow groundwater in Kampala, Uganda. Water Res. 2003, 37 (14), 34213429.

(53) Stanton, B. F.; Clemens, J. D.; Aziz, K. M. A.; Rahman, M. Twenty-four-hour recall, knowledge-attitude-practice questionnaires, and direct observations of sanitary practices: A comparative study. Bull. World Health Organization 1987, 65 (2), 217.

(54) Enger, K. S.; Nelson, K. L.; Rose, J. B.; Eisenberg, J. N. S. The joint effects of efficacy and compliance: A study of household water treatment effectiveness against childhood diarrhea. Water Res. 2013, 47 (3), 1181-1190.

(55) Hunter, P. R. Household water treatment in developing countries: comparing different intervention types using metaregression. Environ. Sci. Technol. 2009, 43 (23), 8991-8997. 